Arq. Bras. Med. Vet. Zootec., v.66, n.2, p.631-634, 2014

\title{
Comunicação
}

[Communication]

\section{Infecção congênita em cabritos por Mycoplasma agalactiae}

\author{
[Congenital infection by Mycoplasma agalactiae in goat kids] \\ N.S. Silva ${ }^{1}$, E.O. Azevedo ${ }^{2}$, A.C. Campos $^{3}$, A.A. Cordeiro ${ }^{1}$, A.G. Mamede ${ }^{1}$, \\ R.B.S. Silva ${ }^{1}$, R.S. Castro ${ }^{4}$, E. Rosendo Nascimento ${ }^{5}$, M.L. Marinho ${ }^{2}$ \\ ${ }^{1}$ Aluno de pós-graduação - Centro de Saúde e Tecnologia Rural - UFCG - Patos, PB \\ ${ }^{2}$ Centro de Saúde e Tecnologia Rural - Universidade Federal de Campina Grande - CSTR-UFCG - Patos, PB \\ ${ }^{3}$ Aluna de pós-graduação - UFRPE - Recife, PE \\ ${ }^{4}$ Universidade Federal Rural de Pernambuco - Recife, PE \\ ${ }^{5}$ Universidade Federal Fluminense - Niterói, RJ
}

A agalaxia contagiosa (AC) é uma enfermidade que afeta ovinos e caprinos, caracterizada por mastite, seguida de agalaxia, poliartrite, ceratoconjuntivite e, ocasionalmente, aborto e pneumonia. Em princípio, caprinos e ovinos são suscetíveis à infecção natural, sendo que, no Nordeste brasileiro, a doença tem sido registrada em maior quantidade nos caprinos, provavelmente associada à utilização desta espécie para produção de leite (Silva et al., 2010).

M. agalactiae foi isolado de caprinos leiteiros com sinais clínicos característicos no estado da Paraíba, em 2001 (Nascimento et al., 2002). Desde então, a doença tem assumido grande importância na região Nordeste do Brasil, devido às perdas econômicas decorrentes da redução da produção de leite, dos custos com tratamento e da morte de animais (Azevedo et al., 2006).

Pode-se afirmar que a doença atingiu um caráter endêmico na região, visto que tem sido comum a ocorrência de casos em diversos rebanhos, com taxas de prevalência que atingem aproximadamente $70 \%$ em determinadas microrregiões (Alcântara, 2010). Cientes desse fato, os criadores têm adotado medidas sanitárias para controlar a doença, em especial a antibioticoterapia. Essa intervenção, no entanto, quando realizada de forma inapropriada $\mathrm{e}$ por poucos dias, resulta na diminuição da sintomatologia clínica, favorecendo a manutenção de animais infectados nos rebanhos. Silva e Marinho (2011), ao trabalharem com cabras naturalmente infectadas pelo $M$. agalactiae no semiárido paraibano, observaram que casos de aborto não têm relação com o período gestacional, no entanto esses autores levantam a possibilidade de infecção transplacentária devido ao nascimento de dois cabritos com poliartrite.

Diante do exposto, o objetivo deste trabalho é relatar três casos de infecção congênita por $M$. agalactiae em cabritos na região Nordeste do Brasil.

Os casos de AC relatados no presente trabalho foram observados em três cabritos nascidos de três cabras com sintomatologia típica da enfermidade durante a prenhez, na forma de poliartrite das articulações cárpicas, com aumento de volume, da sensibilidade e da temperatura e presença de estralos quando realizados movimentos de flexão-extensão no membro, e mastite clínica bilateral de consistência serosa com presença de grumos. No parto as cabras eram aparentemente normais, após terem sido submetidas a tratamento com antibióticos durante 15 dias. O diagnóstico da infecção nos animais foi realizado mediante isolamento em meio Hayflick modificado, sólido e líquido, e teste imunoenzimático indireto, como descrito por Azevedo et al. (2006) e Campos et

Recebido em 18 de março de 2013

Aceito em 18 de dezembro de 2013

*E-mail: natanaelveterinario@bol.com.br 
al. (2009), respectivamente. Os animais eram pertecentes a duas propriedades, sendo uma localizada no município de Patos, estado da Paraíba, e a outra em Lajes, estado do Rio Grande do Norte. Os cabritos nascidos em Patos apresentaram poliartrite; um deles foi acometido nas articulações cárpica e társica direita, e o outro nas articulações cárpica e coxofemoral. $\mathrm{O}$ cabrito da propriedade de Lajes apresentou poliartrite das articulações cárpicas. As articulações apresentaram inchaço, e o animal sentiu dor à palpação e dificuldade de locomoção, com diminuição dos movimentos de flexão e extensão dos membros. O conteúdo da cápsula articular foi coletado em dois cabritos no momento do nascimento, sendo um de cada propriedade. $\mathrm{O}$ aspecto do líquido articular variou de transparente, em um cabrito, a fibrinopurulento e de coloração amarelada, em outro. No terceiro animal, não foi possível realizar a coleta do líquido articular, apesar do inchaço. Neste animal, foi feita a coleta de suabe nasal.

Após coleta, as amostras foram acondicionadas em tubos estéreis contendo igual volume de solução glicerinada com 2000UI/mL de penicilina e enviadas ao laboratório sob refrigeração. Alíquotas de $50 \mu \mathrm{L}$ de cada amostra foram semeadas em meio Hayflick modificado, sólido e líquido, e incubadas a $37^{\circ} \mathrm{C}$ em microaerofilia, e os cultivos foram submetidos à reação em cadeia da polimerase (PCR) como descrito por Azevedo et al. (2006). As três amostras apresentaram colônias em forma de "ovo frito", não degradaram a arginina, não fermentaram a glicose e foram positivas na PCR específica para M. agalactiae.

Para pesquisa de anticorpos anti-M. agalactiae foi feita coleta de sangue venoso dos cabritos logo após o nascimento, antes da primeira mamada, bem como de suas respectivas matrizes, utilizando-se tubos a vácuo. Esse material foi enviado ao laboratório para centrifugação e obtenção do soro. Após realização do teste imunoenzimático indireto, foi constatado que os três cabritos foram negativos, mas as respectivas matrizes apresentavam altos títulos de anticorpos circulantes.

Embora possível, são poucos os relatos de infecção transplacentária por Mycoplasma spp. em pequenos ruminantes. Bar-Moshe e
Rapapport (1981) descreveram uma forma congênita de artrite purulenta proliferativa em cabritos atribuída a $M$. mycoides subsp. Mycoides, em Israel. Os autores observaram celulite difusa no local da inoculação, febre, poliartrite e morte de cabritos infectados de forma experimental. Mais recentemente, Filioussis et al. (2011) relataram casos de poliartrite congênita em cabritos naturalmente infectados por $M$. agalactiae no norte da Grécia.

No Brasil, têm sido registrados casos de aborto em animais cronicamente infectados, nascimento de crias com sinais clínicos ou aparecimento de sintomas caracteristicos da enfermidade nos primeiros dias de vida (Azevedo et al., 2006; Silva e Marinho, 2011). Entretanto, ainda não haviam sido descritos na literatura casos de nascimento de animais infectados pelo $M$. agalactiae e com sinais clínicos da AC com ausência de anticorpos circulantes.

Em ruminantes, ocorre o bloqueio total da passagem transplacentária de anticorpos, devido ao tipo de placenta presente na espécie, caracterizada como sindesmocorial pelo contato direto do epitélio coriônico com os tecidos uterinos, fazendo com que os neonatos nasçam hipo ou agamaglobulêmicos (Argüello et al., 2004; Lima et al., 2009), fato este que pode justificar a ausência de anticorpos anti- $M$. agalactiae nos cabritos estudados neste trabalho. No entanto, segundo Cebra e Cebra (2005), os pequenos ruminantes nascem com linfócitos funcionais capazes de produzir imunoglobulinas endógenas, mesmo que em baixa intensidade. Essas células desenvolvem a capacidade de responder aos antígenos estranhos ao feto, dentro de aproximadamente 80 dias de gestação. Com isso, pressupõe-se que a infecção intrauterina tenha ocorrido anterior a este período, não possibilitando que o feto desenvolvesse uma resposta imune.

Segundo Madanat et al. (2001), podem abortar devido à inflamação do útero ou podem dar origem a descendentes não viáveis. Contudo, o nascimento de crias infectadas não tem sido registrado corriqueiramente. Isto pode ser atribuído à dificuldade de acompanhamento dos partos e à falta de laboratórios qualificados para realização do diagnóstico de rotina. 
É provável que, nos casos descritos neste trabalho, a infecção tenha ocorrido na fase inicial da gestação, levando a um quadro de tolerância imunológica, em razão do período de formação do sistema imunológico. Entretanto, tal mecanismo não está totalmente elucidado nos casos de infecção por $M$. agalactiae, precisando de mais estudos para esse esclarecimento.
Diante do exposto, pode-se concluir que a infecção congênita por $M$. agalactiae pode resultar no nascimento de crias com sinais clínicos de agalaxia contagiosa e imunotolerantes.

Palavras-chave: caprino, agalaxia contagiosa, poliartrite

\begin{abstract}
This study aimed to report three cases of contagious agalactia (CA) by Mycoplasma agalactiae in goat kids born with polyarthritis. The nanny goats belonging to two different herds presented clinical signs of $C A$ during pregnancy and in parturition they were apparently healthy. The carpal articulations of the three goat kids, the tarsus articulation in one, and thigh-femoral articulation in another showed swelling, pain and impairment of the flexion-extension movements. The articular liquid was collected from two goat kids at birth and revealed a content which varied from transparent to fibrinopurulent, presenting a yellow coloring. The samples were plated on modified Hayflick. The colonies had the appearance of "fried egg" and were confirmed as being M. agalactiae by biochemical tests and 16S rRNA PCR. Blood was collected from three animals soon after birth and submitted to the indirect ELISA test for the determination of the titration of the anti- M. agalactiae antibodies. The results confirmed that the goat kids were infected during pregnancy by M. agalactiae and resulted in the birth of an offspring with clinical signs of $C A$ being immune tolerant.
\end{abstract}

Keywords: caprine, contagious agalactia, polyarthritis

\section{REFERÊNCIAS}

ALCÂNTARA, M.D.B. Soroprevalência da agalaxia contagiosa e vacinação experimental em caprinos. 2010. 52f. Dissertação (Mestrado em Medicina Veterinária) - Universidade Federal de Campina Grande, Patos.

ARGÜELLO, A.; CASTRO, N.; ZAMORANO, M.J. et al. Passive transfer of immunity in kid goats fed refrigerated and frozen goat colostrum and commercial sheep colostrum. Small Rumin. Res., v.54, p.237-241, 2004.

AZEVEDO, E.O.; ALCÂNTARA, M.D.B.; NASCIMENTO, E.R. et al. Contagious agalactia by Mycoplasma agalactiae in small ruminants in Brazil: first report. Braz. J. Microbiol., v.37, p.576-581, 2006.

BAR-MOSHE, B.; RAPAPPORT, E. Observations on Mycoplasma mycoides subsp. mycoides infection in Saanen goats. Isr. J. Med. Sci., v.17, p.537-539, 1981.

CAMPOS, A.C.; TELES, J.A.A.; AZEVEDO, E.O. et al. ELISA protein $\mathrm{G}$ for the diagnostic of contagious agalactia in small ruminants. Small Rumin. Res., v.84, p.70-75, 2009.
CEBRA, C.; CEBRA, M. Enfermidades dos sistemas hematológico, imunológico e linfático (Doenças Multissistêmicas). In: PUGH, D.G. (Ed). Clínica de ovinos e caprinos. São Paulo: Roca, 2005. p.401-439.

FILIOUSSIS, G.; GIADINIS, N.D.; PETRIDOU, E.J. et al. Congenital polyarthritis in goat kids attributed to Mycoplasma agalactiae. Vet. Record, v.169, p.364, 2011.

LIMA, A.L.; PAULETTI, P.; SUSIN, I.; MACHADO-NETO, R. Flutuação das variáveis séricas em cabras e estudo comparativo da absorção de anticorpos em cabritos recémnascidos utilizando colostro bovino e caprino. Rev. Bras. Zootec., v.38, p.2211-2217, 2009.

MADANAT, A.; ZENDULKOVÁ, D.; POSPÍSIL, Z. Contagious agalactia of sheep and goats. A review. Acta Vet. Brno., v.70, p.403-412, 2001.

NASCIMENTO, E.R.; BARRETO, M.L.; PLATENIK, M.O. et al. Contagious agalactia by Mycoplasma agalactiae in goats in Brazil. Etiologic study. In: CONGRESS OF INTERNATIONAL ORGANIZATION FOR MYCOPLASMOLOGY, 14., 2002, Vienna. Anais...Vienna: IOM, 2002. p.45-46. (Resumo). 
SILVA, N.S.; MARINHO, M.L. Comparação entre a ação terapêutica do bioterápico de Mycoplasma agalactiae e tilosina/oxitetraciclina em caprinos com agalaxia contagiosa dos ovinos e caprinos. In: CONGRESSO DE INICIAÇÃO CIENTIFICA DA UNIVERSIDADE FEDERAL DE CAMPINA GRANDE, 8., 2011, Campina Grande. Anais... Campina Grande: UFCG, 2011.

SILVA, N.S.; MARINHO, M.L.; ALMEIDA, A.P.; LUCENA, E.A. Avaliação clínica da eficácia do tratamento da agalaxia contagiosa dos ovinos e caprinos com bioterápico de Mycoplasma agalactiae em caprinos. In: CONGRESSO DE INICIAÇÃO CIENTIFICA DA UNIVERSIDADE FEDERAL DE CAMPINA GRANDE, 7., 2010, Campina Grande. Anais... Campina Grande: UFCG, 2010. 